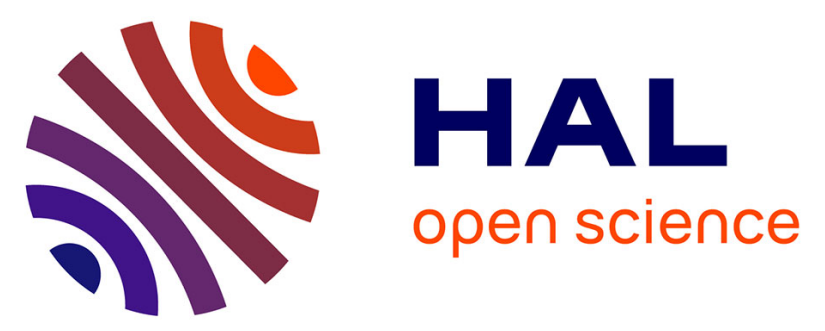

\title{
Synthesis of Indolizine and Pyrrolo[1,2- a ]azepine Derivatives via a Gold(I)-Catalyzed Three-Step Cascade
}

Fatih Sirindil, Stéphane Golling, Raphaël Lamare, Jean-Marc Weibel, Patrick Pale, Aurélien Blanc

\section{- To cite this version:}

Fatih Sirindil, Stéphane Golling, Raphaël Lamare, Jean-Marc Weibel, Patrick Pale, et al.. Synthesis of Indolizine and Pyrrolo[1,2- a ]azepine Derivatives via a Gold(I)-Catalyzed Three-Step Cascade. Organic Letters, 2019, 10.1021/acs.orglett.9b03402 . hal-02347330

\section{HAL Id: hal-02347330 \\ https://hal.science/hal-02347330}

Submitted on 5 Nov 2019

HAL is a multi-disciplinary open access archive for the deposit and dissemination of scientific research documents, whether they are published or not. The documents may come from teaching and research institutions in France or abroad, or from public or private research centers.
L'archive ouverte pluridisciplinaire HAL, est destinée au dépôt et à la diffusion de documents scientifiques de niveau recherche, publiés ou non, émanant des établissements d'enseignement et de recherche français ou étrangers, des laboratoires publics ou privés. 


\title{
Synthesis of Indolizine and Pyrrolo[1,2-a]azepine Derivatives via a Gold(I)-Catalyzed 3-Step Cascade
}

\author{
Fatih Sirindil, Stéphane Golling, Raphaël Lamare, Jean-Marc Weibel, Patrick Pale, and Aurélien \\ Blanc*
}

Laboratoire de Synthèse, Réactivité Organiques et Catalyse, Institut de Chimie, UMR 7177 - CNRS, Université de Strasbourg, 4 rue Blaise Pascal, 67070 Strasbourg, France.

Supporting Information Placeholder
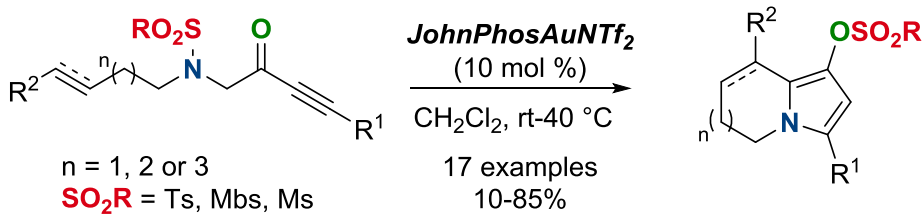

ABSTRACT: Linear $N$-alkenyl or alkynyl $N$-sulfonyl 1-aminobut-3-yn-2-ones are converted into bicyclic indolizines and pyrrolo[1,2-a]azepine-type alkaloids upon gold(I) catalysis (17 examples, 10-85\%). The reaction cascade allowed to form C$\mathrm{N}, \mathrm{O}-\mathrm{S}$ and C-C bonds via a cycloisomerization/sulfonyl migration/cyclization process using 10 mol \% of [(2-biphenyl)ditert-butylphosphine]gold(I) triflimide complex in dichloromethane.

Alkaloids constitute a huge family of natural products. Among them, indolizines and their saturated analogs are commonly distributed in nature, especially in plants (Figure 1). ${ }^{1}$ These alkaloids exhibit numerous biological activities and have thus been the focus of various synthetic studies and numerous analogs have been produced. ${ }^{2}$ Rosabulin (STA-5312) ${ }^{3}$ or rhazinilam ${ }^{4}$ are typical examples, developed as anticancer agents possessing a microtubule inhibitor activity. Isolated from the poison gland secretions of Myrmicaria ants, the poisonous myrmicarin alkaloid family represent another example. ${ }^{5}$

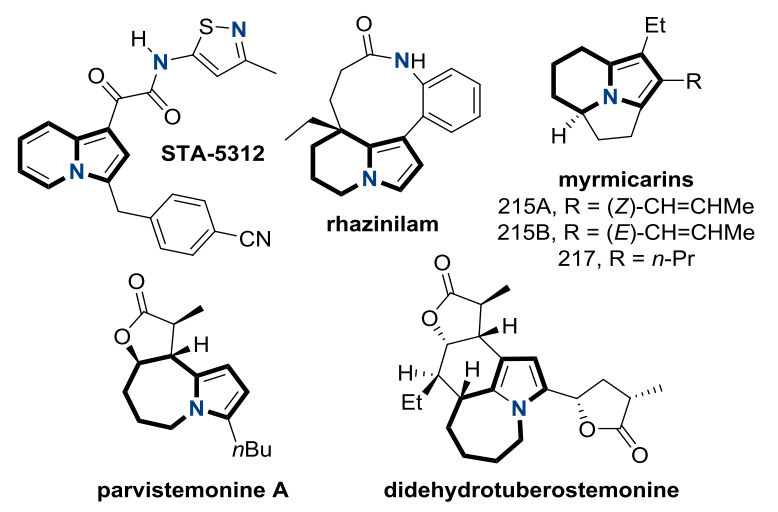

Figure 1. Representative natural and bioactive products with hydroindolizine or pyrrolo[1,2-a]azepine scaffolds.

Although analogs to indolizine derivatives, pyrrolo[1,2a]azepine derivatives are far less represented in nature. Such motif can be found in the large family of Stemona alkaloids, ${ }^{6}$ isolated from Stemonaceae plants. Used in traditional Chinese medicine to treat bronchitis, tuberculosis and parasite-induced illness, these alkaloids exhibit diverse physiological properties, as with the antiparasitic parvistemonine $A^{7}$ or the insecticidal didehydrotuberostemonine ${ }^{8}$.

Scheme 1. Synthetic Strategies Towards Ring-Fused Pyrroles via Gold-Catalyzed Cyclisation/N-to-O Sulfonyl Migration.

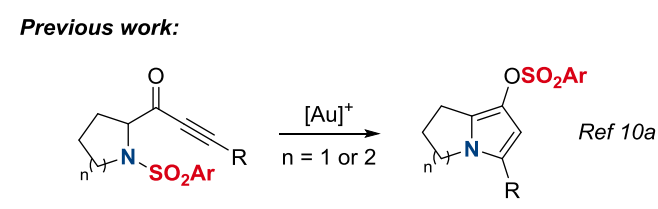

This work:

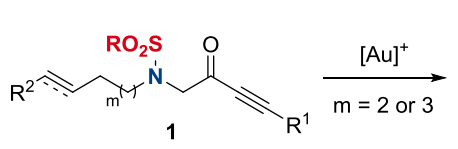<smiles>[R]Oc1cc([R2])n2c([R])cccc12</smiles>

The gold-catalyzed ${ }^{9}$ cyclization-sulfonyl migration cascade $^{10}$ we recently developed offers a unique opportunity to design a new synthetic route to indolizine and azepine type alkaloids. This cascade could indeed provide a mild and efficient access to sulfonylated pyrroles (Scheme 1, top) and if the nitrogen atom of the latter carries an unsaturated chain, gold may promote a third step. A cyclization involving the newly created pyrrole and this activated unsaturation would furnish 1-azabicyclo[n.3.0]alkane derivatives ( $n=4$ or 5 ), depending on the chain length (Scheme 1, bottom). Furthermore, the so-formed motif should carry a sulfonate group, allowing for direct modification through Suzuki-Miyaura-type coupling reaction. ${ }^{10 \mathrm{~b}}$ 
We report here the implementation of this gold(I)catalyzed cascade toward the synthesis of substituted and/or functionalized hydroindolizines or pyrrolo[1,2a]azepines 2 from linear $N$-alkenyl or alkynyl $N$-sulfonyl 1aminobut-3-yn-2-ones $\mathbf{1}$.

Table 1. Optimization of the Reaction Conditions.
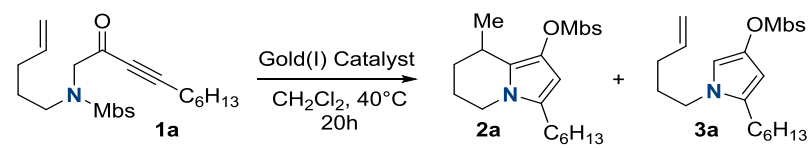

Mbs = 4-methoxybenzenesulfonate

\begin{tabular}{|c|c|c|c|}
\hline entry & catalyst (mol \%) & $\begin{array}{c}\text { yield } \mathbf{2 a}+\mathbf{3 a} \\
(\%)^{a}\end{array}$ & $\begin{array}{l}\text { ratio } \\
\mathbf{2} \mathbf{a}: 3 \mathbf{a}^{b}\end{array}$ \\
\hline 1 & $\mathrm{Ph}_{3} \mathrm{PAuNTf}_{2}(5)$ & 57 & $0: 100$ \\
\hline 2 & $\left(\mathrm{C}_{6} \mathrm{~F}_{5}\right)_{3} \mathrm{PAuNTf}_{2}(5)$ & 13 & $0: 100$ \\
\hline 3 & $\begin{array}{c}{\left[(2,4-t \mathrm{BuPhO})_{3} \mathrm{P}\right.} \\
\mathrm{Au}(\mathrm{MeCN})] \mathrm{NTf}_{2}(5)\end{array}$ & 18 & $0: 100$ \\
\hline 4 & IPrAuNTf $_{2}(5)$ & 44 & $33: 67$ \\
\hline 5 & $\begin{array}{c}{[\mathrm{IPrAu}(\mathrm{MeCN})]} \\
{\left[\mathrm{PMo}_{12} \mathrm{O}_{40}\right]\left[\mathrm{H}_{2}\right](5)}\end{array}$ & 27 & 100:0 \\
\hline 6 & $\mathrm{XPhosAuNTf}_{2}(5)$ & 19 & $100: 0$ \\
\hline 7 & CyJohnPhosAuNTf 2 (5) & 55 & $90: 10$ \\
\hline 8 & JohnPhosAuNTf 2 (5) & 72 & $90: 10$ \\
\hline 9 & JohnPhosAuCl/AgSbF 6 (5) & 24 & 100:0 \\
\hline 10 & JohnPhosAuNTf 2 (10) & 81 & 100:0 \\
\hline
\end{tabular}

${ }^{a}$ Calculated yield from ${ }^{1} \mathrm{H}$ NMR integration relative to an internal standard (dimethyl terephthalate). ${ }^{b}$ The ratio was determined from the ${ }^{1} \mathrm{H}$ NMR spectrum of crude reaction.

For the screening of the reaction conditions, we selected the $N$-pent-4-enyl $N$-4-methoxybenzenesulfonyl 1aminobut-3-yn-2-one 1a, readily prepared in 4 steps from methyl glycinate (see Supporting Information). 1a was submitted to different gold complexes as catalyst (Table 1). Previously reported to promote the cyclization-sulfonyl migration reaction, ${ }^{10}$ the Gagosz catalyst ${ }^{11}$ only provided the pyrrole intermediate $3 \mathbf{a}$ in dichloromethane at $40^{\circ} \mathrm{C}$ (entry 1). The more electron withdrawing tri(fluorophenyl)phosphine analog as well as a phosphite analog also gave the sole pyrrole $\mathbf{3 a}$, but in low yields (entries 2-3). Gold carbene complexes allowed reversing the selectivity, with a surprisingly dramatic effect of the counterion. Indeed, with a triflimide, a mixture of pyrrole $\mathbf{3} \mathbf{a}$ and the expected bicyclic product $\mathbf{2} \mathbf{a}$ was produced in a $1: 2$ ratio, while with a polyoxometalate as anion, ${ }^{12}$ only the expected bicyclic product was observed, unfortunately in modest yield along with degradation products (entry 4 vs 5). Shifting to Buchwald-type ligand also reversed the selectivity but with more interesting results. The large XPhos ligand promoted the sole formation of the bicyclic product $\mathbf{2 a}$, but again with modest yield (entry 6). Using the less hindered CyJohnPhos ligand increased the reactivity and the overall yield but with a slightly lower selectivity (entry 7 vs 6). Switching to JohnPhos ligand with different steric parameter ${ }^{13}$ rewardingly provided even higher reactivity and yield, in favor of the expected bicyclic product 2a, but again not fully selectively (entry 8). Changing the $\mathrm{NTf}_{2}$ anion to $\mathrm{SbF}_{6}$ increased the selectivity, with only the bicycle formed, but to the detriment of yields (entry 9). Unfortunately, the compounds $\mathbf{2 a}$ and $\mathbf{3 a}$ were inseparable by chromatography. Therefore, we tried to improve the selectivity by performing the reaction with $10 \mathrm{~mol} \%$ of JohnPhosAuNTf 2 catalyst (entry 10) and we were please to obtain 2a with a total selectivity and with high yield. This catalyst was thus used for exploring the scope of this reaction.

With the optimized conditions in hand, various substrates carrying $N$-alkenyl or $N$-alkynyl chain were prepared 1a-p (see Supporting Information) and engaged in the new gold-catalyzed cycloisomerization-sulfonyl migration-cyclisation cascade (Scheme 2).

Scheme 2. Reaction Scope of the Cascade with Terminal $N$ Alkenyl or Alkynyl $N$-Sulfonyl 1-Aminobut-3-yn-2-one Derivatives $\mathbf{1}^{a}$
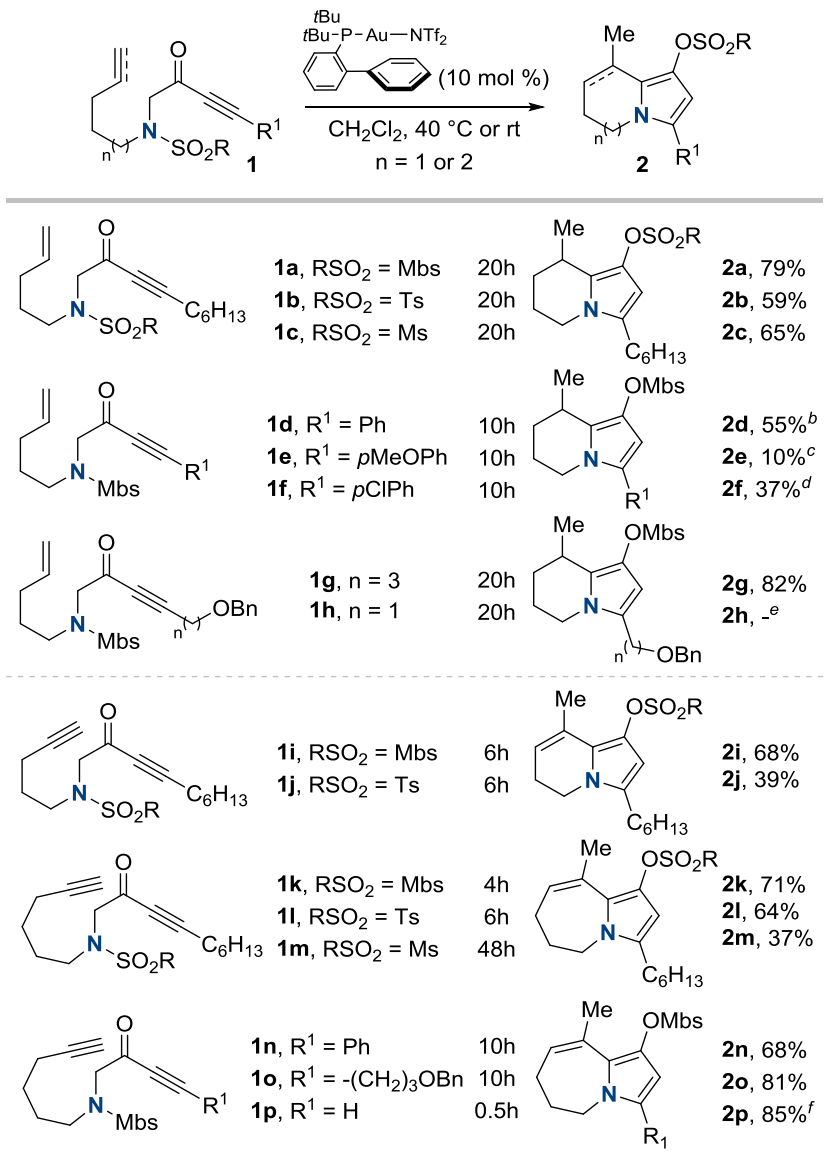

${ }^{a}$ Reactions run at $40^{\circ} \mathrm{C}$ for $N$-alkenyl derivatives or at room temperature for $N$-alkynyl derivatives, $c=0.1 \mathrm{~mol} / \mathrm{L}$. ${ }^{b}$ Isolated along $10 \%$ of pyrroles intermediate $3 \mathbf{d}$ (See Supporting Information). ${ }^{c}$ Calculated yield from ${ }^{1} \mathrm{H}$ NMR integration relative to an internal standard (dimethyl terephthalate). ${ }^{d}$ Partial degradation occurs during purification. ${ }^{e}$ Degradation occurs. fCumulative yield with the exo-methylene product.

Considering the importance of the sulfonyl group for the migration step, ${ }^{10 a, 14}$ its influence was first examined. As shown with $N$-pent-4-enyl substrates 1a-c, the paramethoxybenzenesulfonate (Mbs) gave the best result, providing the expected bicycle $2 \mathrm{a}$ in high yield. In contrast, the tosylate (Ts) and mesylate (Ms) derivatives 1b-c furnished, after $20 \mathrm{~h}$ at $40{ }^{\circ} \mathrm{C}$, mostly the bicyclic products $2 \mathrm{~b}$ 
and $2 \mathbf{c}$ in an average yield of $60 \%$ but together with $5 \%$ of pyrrole intermediates 3 . The Mbs sulfonate was thus used to explore functional compatibility.

With a phenyl group as substituent of the alkyne, the cascade proceeded as well, but the conjugation of this group to the formed pyrrole $\mathbf{3 d}$ lowered the nucleophilicity of this pyrrole, and thus some pyrrole was left, lowering the yield of the expected bicyclic product $\mathbf{2 d}$. The substrates $\mathbf{1 e}$ and $\mathbf{1 f}$, possessing respectively electron withdrawing $(\mathrm{Cl})$ or donating (OMe) groups on the aryl part, were more problematic. Indeed, the tetrahydroindolizine $\mathbf{2 e}$ was only obtained in low yield along with many degradation products, while compound 2f proved highly instable and could only be isolated in modest yield, despite a clean reaction observed by NMR.

With a protected hydroxy group, the cascade was very effective, only giving the corresponding bicycle $\mathbf{2 g}$ in high yield, but only when this functional group is remote from the alkyne moiety. When such functional group is at the propargylic position, degradation occurred (2h vs $\mathbf{2 g}$ ).

$N$-Alkynyl chains were then evaluated. Substrates carrying such chain proved more reactive and the reactions were conducted at room temperature. The $N$-pent-4-ynyl chain induced a 6-exo-dig cyclization in good yield with the Mbs derivative 1i, but in modest yield with the $N$-tosyl analog 1j. Structural analysis of these products revealed that the resulting double bond in such products was internal to the newly created cycle, despite exo-cyclization. This could be the result of double bond migration, probably assisted by the catalyst. Interestingly, the longer $N$-hex-4ynyl chain also allowed exo-dig cyclization, which provided in good yields dihydropyrrolo[1,2-a]azepine compounds 2k-p, here again after double bond migration. As in the $N$ alkenyl series, changing the tosylate or mesylate for the para-methoxybenzenesulfonate improved the cyclization efficiency and yield (2k vs $\mathbf{2 l - m}$ ). Modification of the ynone was perfectly tolerated as attested by the good yields obtained for bicyclic products $\mathbf{2 n - p}$. It is worth noticing that in this $N$-alkynyl series, the bicyclic products contain a double bond, which can be further functionalized.

The influence of the chain length as well as the substitution of the alkene or alkyne function were then investigated (Scheme 3). With a shorter $N$-but-4-enyl chain, the substrates $\mathbf{1 q}$ and $\mathbf{1 r}$ still provide the tetrahydroindolizine system, although in modest yields. The cyclization still proceeded, but in a 6-endo-trig process instead of the 6exo-trig cyclisation observed with the $N$-pent-4-enyl chain. With the longer $N$-hex-4-enyl chain (1s) or with substituted alkene such as in the (E)- $N$-(hex-4-en-1-yl) chain (1t), the cascade stopped at the pyrrole stage and no bicyclic product could be detected.

The $N$-but-4-ynyl chain $(\mathbf{1 u})$ also allowed a 6-endo-dig cyclization, but in very low yield mostly due to the high instability of the so-formed dihydroindolizine $\mathbf{2 u}$. However, the cascade was efficiency restored with internal alkynes $(\mathbf{1 v}-\mathbf{w})$, as showed by the formation of the expected dihydroindolizines $\mathbf{2 v}$ and $\mathbf{2 w}$ in good yields.

Scheme 3. Synthesis of Indolizine Derivatives from Linear $N$-Enyl or Ynyl $N$-Sulfonyl 1-Aminobut-3-yn-2-ones 1q-v and Limitations. ${ }^{a}$
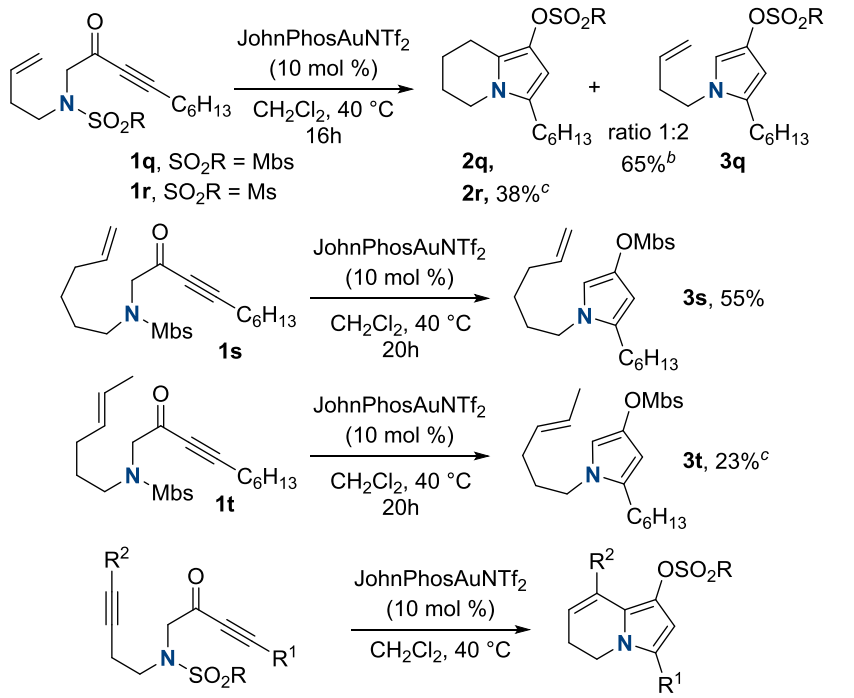

1u, $\mathrm{RSO}_{2}=\mathrm{Ts}, \mathrm{R}^{1}=\mathrm{C}_{6} \mathrm{H}_{13}, \mathrm{R}^{2}=\mathrm{H} \quad 6 \mathrm{~h} \quad \mathbf{2 u}, 11 \%$, d 1v, $\mathrm{RSO}_{2}=\mathrm{Mbs}, \mathrm{R}^{1}=\mathrm{C}_{6} \mathrm{H}_{13}, \mathrm{R}^{2}=\mathrm{Et} \quad 16 \mathrm{~h} \quad \mathbf{2 v}, 71 \%$ $\mathbf{1 w}, \mathrm{RSO}_{2}=\mathrm{Ts}, \mathrm{R}^{1}=\mathrm{C}_{3} \mathrm{H}_{7}, \mathrm{R}^{2}=\mathrm{Et} \quad 16 \mathrm{~h} \quad \mathbf{2 w}, 53 \%$

${ }^{a} \boldsymbol{C}=0.1 \mathrm{~mol} / \mathrm{L} .{ }^{b}$ Cumulative yield of inseparable $\mathbf{2 q}$ and $\mathbf{3 q}$ derivatives. ${ }^{c}$ Degradation occurs. ${ }^{d}$ Calculated yield from ${ }^{1} \mathrm{H}$ NMR integration relative to an internal standard (dimethyl terephthalate).

The mechanism of this cascade was postulated to begin by the $\pi$-activation of the ynone substrate 1 by gold(I) catalyst (Scheme 4). Intramolecular ammonium formation of the alkyne ${ }^{15}$ could then occur leading to the transient vinylgold ammonium intermediate $\mathbf{A}$. At this stage, the intramolecular sigmatropic $N$-to- $O$ migration of the sulfonyl group took place affording the sulfonylated pyrrole intermediate B. ${ }^{10}$ Finally, the nucleophilic addition of the electron-rich pyrrole motif to the remaining unsaturation activated by gold furnished the bicyclic product $2 .{ }^{16}$ Further isomerization of the double bond also occurred when starting from $N$-alkynyl substrates.

Scheme 4. Proposed Mechanism for the Formation of Indolizine and Pyrrolo[1,2-a]azepine via Gold(I)-Catalyzed Cascade.

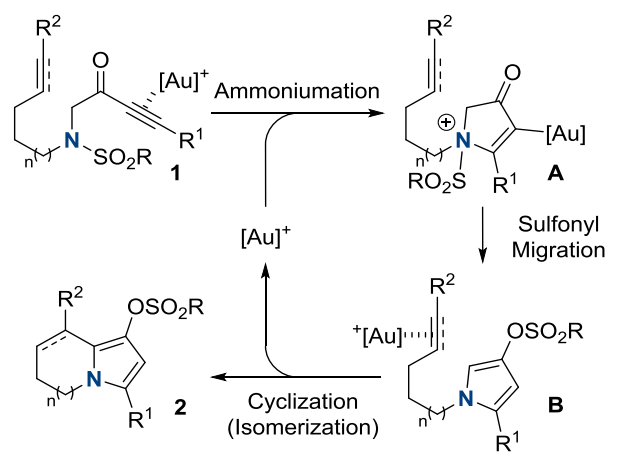

In conclusion, we developed a new 3 step gold-catalyzed cascade from readily available compounds derived from glycine. The cycloisomerization of $\mathrm{N}$-alkenyl or alkynyl $\mathrm{N}$ sulfonyl 1-aminobut-3-yn-2-ones followed by a $\mathrm{N}$-to- $\mathrm{O}$ sulfonyl migration provided $N$-alkenyl or alkynyl pyrrolyl sulfonates and a further cyclization afforded functionalized 
indolizines or pyrrolo[1,2-a]azepines in good to high yields.

\section{ASSOCIATED CONTENT}

The Supporting Information is available free of charge on the ACS Publications website.

Experimental details, copies of spectra (PDF).

\section{AUTHOR INFORMATION}

\section{Corresponding Author}

ablanc@unistra.fr

ORCID

Aurélien Blanc: 0000-0003-4240-3281

Patrick Pale: 0000-0002-3924-530X

\section{Notes}

The authors declare no competing financial interest.

\section{ACKNOWLEDGMENT}

We gratefully acknowledge the French Ministry of Research and the CNRS for financial support. The authors thank Delphine Hatey (Institut de Chimie, University of Strasbourg) for the preparation of compound 1p. F. S. thanks the French Ministry of Research for PhD fellowship.

\section{REFERENCES}

(1) (a) Sandeep, C.; Venugopala, K. N.; Khedr, M. A.; Attimarad, M.; Padmashali, B.; Kulkarni, R. S.; Venugopala, R.; Odhav, B., Review on chemistry of natural and synthetic indolizines with their chemical and pharmacological properties. J. Basic Clin. Pharm. 2017, 8, 49. (b) Michael, J. P., Indolizidine and quinolizidine alkaloids. Nat. Prod. Rep. 2008, 25, 139.

(2) (a) Majumdar, K. C.; Chattopadhyay, S. K.; Eds Heterocycles in Natural Product Synthesis, 2011. (b) Sadowski, B.; Klajn, J.; Gryko, D. T., Recent advances in the synthesis of indolizines and their p-expanded analogues. Org. Biomol. Chem. 2016, 14, 7804.

(3) Li, H.; Xia, Z.; Chen, S.; Koya, K.; Ono, M.; Sun, L., Development of a practical synthesis of STA-5312, a novel indolizine oxalylamide microtubule inhibitor. Org. Process Res. Dev. 2007, $11,246$.

(4) David, B.; Sevenet, T.; Morgat, M.; Guenard, D.; Moisand, A.; Tollon, Y.; Thoison, O.; Wright, M. Rhazinilam mimics the cellular effects of taxol by different mechanisms of action. Cell Motil. Cytoskeleton. 1994, 28, 317.

(5) (a) Schroeder, F.; Franke, S.; Francke, W.; Baumann, H.; Kaib, M.; Pasteels, J. M.; Daloze, D., A new family of tricyclic alkaloids from Myrmicaria ants. Tetrahedron 1996, 52, 13539. (b) Ondrus, A. E.; Movassaghi, M., Total synthesis and study of myrmicarin alkaloids. Chem. Commun. 2009, 4151.

(6) (a) Kaltenegger, E.; Brem, B.; Mereiter, K.; Kalchhauser, H.; Kahlig, H.; Hofer, O.; Vajrodaya, S.; Greger, H., Insecticidal pyrido[1,2-a]azepine alkaloids and related derivatives from Stemona species. Phytochem. 2003, 63, 803. (b) Pilli, R. A.; Rosso, G. B.; Ferreira de Oliveira, M. d. C., The chemistry of Stemona alkaloids: An update. Nat. Prod. Rep. 2010, 27, 1908. (c) Greger,
H., Structural classification and biological activities of Stemona alkaloids. Phytochem. Rev. 2019, 18, 463.

(7) Huang, S.-Z.; Kong, F.-D.; Ma, Q.-Y.; Guo, Z.-K.; Zhou, L.-M.; Wang, Q.; Dai, H.-F.; Zhao, Y.-X., Nematicidal Stemona alkaloids from Stemona parviflora. J. Nat. Prod. 2016, 79, 2599.

(8) Lin, W.; Ye, Y.; Xu, R., Chemical studies on new Stemona alkaloids, IV. Studies on new alkaloids from Stemona tuberosa. J. Nat. Prod. 1992, 55, 571.

(9) (a) Gold Catalysis: An Homogeneous Approach; Toste, F. D., Michelet, V., Eds.; Catalytic Science Series 13, Imperial College Press, 2014. (b) Modern Gold Catalyzed Synthesis; Toste, F. D., Hashmi, A. S. K., Eds.; Wiley-VCH, 2012. (c) Stephen, A.; Hashmi, K.; Hutchings, G. J. Gold catalysis. Angew. Chem., Int. Ed. 2006, 45, 7896.

(10) (a) Miaskiewicz, S.; Gaillard, B.; Kern, N.; Weibel, J.-M.; Pale, P.; Blanc, A. Gold(I)-catalyzed $N$-desulfonylative amination versus $N$-to- $O$ 1,5-sulfonyl migration: A versatile approach to 1 azabicycloalkanes. Angew. Chem. Int. Ed. 2016, 55, 9088. (b) Sirindil, F.; Weibel, J.-M.; Pale, P.; Blanc, A Total synthesis of rhazinilam through gold-catalyzed cycloisomerization-sulfonyl migration \& palladium-catalyzed Suzuki-Miyaura coupling of pyrrolyl sulfonates. Org. Lett. 2019, 21, 5542.

(11) Mézailles, N.; Louis Ricard, L.; Fabien Gagosz, F. Phosphine Gold(I) bis-(trifluoromethanesulfonyl)imidate complexes as new highly efficient and air-stable catalysts for the cycloisomerization of enynes. Org. Lett. 2005, 7, 4133.

(12) Sirindil, F.; Nolan, S. P.; Dagorne, S.; Pale, P.; Blanc, A.; de Fremont, P. Synthesis, characterization and catalytic activity of NHC gold(I) polyoxometalate complexes. Chem. Eur. J. 2018, 24, 12630.

(13) Christian, A. H.; Niemeyer, Z. L.; Sigman, M. S.; Toste, F. D. Uncovering subtle ligand effects of phosphines using gold(I) catalysis. ACS Catal. 2017, 7, 3973.

(14) For related examples of functional group migration across alkynes, see: Patil, N. T.; Kavthe, R. D.; Yamamoto, Y., Metalcatalyzed intramolecular heteroatom $(\mathrm{X}) \rightarrow$ carbon $(\mathrm{C})$ functional group migration reactions involving additions of X-Y bonds across alkynes. Adv. Heterocycl. Chem. 2010, 101, 75.

(15) (a) Miaskiewicz, S.; Weibel, J.-M.; Pale, P.; Blanc, A. Gold(I)catalyzed cyclization/nucleophilic Substitution of 1- $(\mathrm{N}-$ sulfonylazetidin-2-yl) ynones into $\mathrm{N}$-sulfonylpyrrolin-4-ones. $\mathrm{Org}$. Lett. 2016, 18, 844. (b) Pertschi, R.; Miaskiewicz, S.; Weibel, J.-M.; Pale, P.; Blanc, A. Gold(I)-catalyzed cascade: synthesis of 2,5disubstituted pyrroles from $\mathrm{N}$-sulfonyl-2-(1ethoxypropargyl)azetidines through cyclization/nucleophilic substitution/elimination. Synthesis 2017, 49, 4151. (c) Pertschi, R.; Weibel, J.-M.; Pale, P.; Blanc, A., Benzosultam synthesis by gold(I)-catalyzed ammonium formation/nucleophilic substitution. Org. Lett. 2019, 21, 5616.

(16) It is noteworthy that pyrrole derivatives have been reported to cyclize on allenes upon gold(I) activation, see: (a) Liu, Z.; Wasmuth, A. S.; Nelson, S. G., Au(I)-Catalyzed Annulation of Enantioenriched Allenes in the Enantioselective Total Synthesis of (-)-Rhazinilam. J. Am. Chem. Soc. 2006, 128, 10352. (b) Magne, V.; Lorton, C.; Marinetti, A.; Guinchard, X.; Voituriez, A., Short enantioselective total synthesis of (-)-Rhazinilam using a gold(I)catalyzed cyclization. Org. Lett. 2017, 19, 4794. 